\title{
Power, Politics, Possibilities Thoughts Toward Creating a Black Digital Oral History Archive
}

\author{
ANNETTE HENRY \\ University of British Colombia
}

\begin{abstract}
Great dissonances and inequities can be created by power relationships and cultural misunderstandings. In this essay, in an attempt to preempt problems that stem from a lack of attention to questions of equity, I consider the possible pitfalls of a partnership with a Black community organization in anticipation of a project: The co-creation of a digital Black oral history archive. Political, cultural, and ethical issues that undergird equity are raised, such as researcher-insider positionality, trust, custodianship of others' materials, representation of participants' language varieties and voice, the use of technology, and the politics of housing a Black community archive at the University of British Columbia.
\end{abstract}

Keywords

digital archives, oral history, race, representation, community collaboration

Introduction

Do we really want a social history of society which is empty of its people and which does not reflect real lives and experiences because that is the sort of history the use of formal archives often produces? (Flinn, 2007, p. 160)

In Canada we are witnessing a burgeoning of innovative textual forms produced by, and that focus on, historically marginalized groups. These texts give a fuller view of what it means to be Canadian, and in many cases, a member of a diaspora, as well as what it means to live, work, and be educated in this country. Black authors, artists, and activists in British Columbia, such as David Chariandy, Wayde Compton, Afuwa Granger, Juliane Okot Bitek, and Cecily Nicholson, to name a few, are contributing to this exciting, growing corpus of works that address experiences and histories ignored in the mainstream. Vancouver grassroots activist project The Hogan's Alley Memorial Project (Compton, 2002), along with performances such as James Douglas: An opera (Jones-Darrell, 2017), exemplify projects that highlight ignored B.C. histories. These efforts and others throughout the province are contributing to a larger river of grassroots and institutional Black historical and archival materials, found online and in cultural centres and informal spaces throughout the country (e.g., the Ontario Black History Society and the Black Loyalist Heritage Centre in Nova Scotia). These works can offer alternative resources for activist educators and researchers ever-seeking artifacts and curricula that are oppositional to the current institutional, Eurocentric knowledge system. I hope to contribute to this creative and intellectual textual production in British Columbia through creating a digital oral history archive that stems from a Black community initiative.

The project is in its beginning stages. (I shall discuss the research process later, but mention briefly here that these initial tasks have involved digitizing interviews and some 
transcriptions.) New findings and insights, then, are not possible at this time- - so why discuss the project at this embryonic stage? I believe these beginning moments and musings are precisely the times to consider the ways in which we envision our work and relationships in communities. These considerations are ever-relevant to university researchers who espouse goals of equitable, respectful, and socially just projects. These aspirations are at the heart of how we frame our commitments and embark on projects for social change.

In this essay, I want to raise issues and preempt problems regarding potential ethical and procedural concerns that might arise in working towards a digital archive with the oftdisregarded Black community. My thirty years of conducting research in various Black communities in Canada and the United States have taught me to tread softly and recognize how easily the expectations imposed on researchers by universities and those expressed by community groups may differ. Specifically, I focus here on "equity" issues within a community that researchers have often portrayed negatively or erroneously. "Equity" has become institutionalized in the neoliberal university and a substitute for "diversity," both of which avoid necessary discussions of race (Henry, Dua, James, Kobayshi, Smiith \& Ramos, 2017). Equity involves politics. Equity involves ethics.

I shall first briefly describe the community with whom I am working, the theoretical lenses that frame the project, and the qualitative methods that I bring to the project. Then I will discuss some of the thorny ethical tensions I hope to avoid in developing a digital community archive.

\section{Who is This Community?}

The National Congress of Black Women Foundation (NCBWF) is a welcomed oasis for many newcomers and citizens in Metro Vancouver. It is a nonprofit organization located in Burnaby. It launches programs and activities that foster the development of healthy youth and families in B.C. The executive director, Nalda Callendar, has loaned me 90 audiotapes, including 59 oral history interviews conducted between 2006 and 2007. The interviewees range in age from 28 to 85 . They come from a variety of professions-such as teachers, professors, singers, actors, lawyers, doctors, writers, postal workers, and entrepreneurs. Some participants were born in Vancouver; others migrated from other parts of Canada or abroad. Consider the following ways they name themselves: "Black," "Jamaican, "Chinese Jamaican,” "Black man,” “African,” "Biracial, “ "Caribbean, European, Aboriginal," “Afro-Canadian," "Descendant of enslavement, Jamaican/English/Scottish/unknown west African," "Human Race," and "Belizean Creole.” These identifications reflect the global and transnational tapestry of peoples and places in British Columbia. They also reflect the politics of naming and un-naming, and the variegations of Blackness. We are not a homogeneous group.

I hope that the project will open up new ways of thinking about Canadian Blackness amid this particular demographic ${ }^{1}$ and in this geographic location that has been called the

\footnotetext{
${ }^{1}$ The Black population of Metro Vancouver is indeed small, reflecting the national average of about 2\%unlike Canada's two other major cities, Toronto and Montreal, with Black populations of 8\% and 9\%, respectively. The region is projected to be a city with more racialized people than whites by 2031 (Statistics Canada, 2010) and the influx of Black populations is rapidly changing the demographic and linguistic landscape (Creese, 2015; The Environics Institute, 2017).
} 
Black Pacific (e.g., Smyth, 2014) ${ }^{2}$. Vancouver writer Wayde Compton calls this unique corner of the world "the diaspora's upper left hand-margin" (Compton, 2007, p. 493). Also, as one of the interviewees, Compton explained in 2006: "This is the riddle I've been trying to solve in all my writing. How racism is unique in this place. How Black identity is unique here. And if that's true, how all the strategies we've inherited from other places aren't all that useful” (p. 14). This excerpt beautifully encapsulates the need for-and possibilities of - examining the specificity of the Black diaspora in British Columbia.

One condition of my collaboration with NCBWF is the production of a book for the organization and the general public - a legacy document. With the development of a Black oral history digital archive, I am bringing a new phase to the project. Based on the ways that youth learn and access materials, these web-based resources and artifacts (including curriculum materials and other digital resources) will be useful. This online resource will have far-reaching use for schools, universities, and community organizations. One can conceive of this project as, to quote David Scott (2008), an "archaeology of Black memory"-more than the collection and organization of narratives, as a process of constructing an institution of memory, or re-membering” (p. vi). This project will provide a unique perspective on recent history; it will feature not only people who have passed away in the $21^{\text {st }}$ century but also people who are currently making contributions to British Columbian society.

The community organization undertook the interview project, with an activist stance, to address the misrepresentation and even erasure of Black people's presence and contributions in British Columbian life. This archive-a community archive-is a counterhegemonic act against the 'business as usual' erasure of Blacks in most archives. Indeed, as Flinn (2007) explains, the term "community archives" refers to "the (often) grassroots activities of creating and collecting, processing, curating, preserving and making accessible collections relating to a particular community or specified subject” (pp. 152154).

\section{Theoretical Perspectives}

I am drawing from several theoretical perspectives: Diaspora theories, critical race feminisms, biographical studies, and sociocultural theories of language. Briefly, current theorizations of diaspora connect the array of conditions and realities that mark relocations, transnational migrations and movements, and globalization processes (James \& Davis, 2013; Trotz \& Mullings, 2013; Zeleza, 2008). This reconceptualization is important in this study that examines entangled histories, "roots, and routes" (DeLoughrey, 2007, p. 163). Critical race feminisms and their emphases on intersectional analyses are also especially useful here, as these narratives highlight the multiple and intersecting dimensions of power and marginalization (Collins, 2009; Crenshaw, 1991; Razack, Smith, \& Thobani, 2010); they are situated within racialized, classed, gendered, and other societal dynamics. Third, I shall use a socio-biographical frame, through which forms of historical writing explore

\footnotetext{
2 "Black Pacific" is a term that has been used to explore among other relationships, Afro-Asian connections in Hawaii (Okihiro, 2006), Oceanic-African/African diasporic connections (Shillam, 2015) as well as AfroPeruvian cultural negotiations (Feldman, 2006). In the Canadian context, Heather Smyth draws on Compton's engagements with Black cultures in Vancouver (e.g., Compton, 2001, 2007, 2011). The Black Pacific denotes a remapping and rethinking of Black geographies. See McKittrick (2002) for a discussion of Black geographies.
} 
both the individual and the broader social context (Hendry, 2010; Salvatore, 2004). Histories are contested terrain (Nóvoa, 1995), most often told from the points of view of the power elite (Okihiro, 2001) —hence the political importance of marginalized Canadians voicing their lived embodiments of identity and difference as these dimensions impact their everyday experiences. Such biographical studies situate racialized, classed, gendered and geopolitical dynamics. Finally, I shall draw on sociolinguistic and sociocultural theories that examine the language of speakers who have migrated from Anglo-Caribbean or African countries, or grew up in households where Creoles or other vernaculars were spoken (Creese \& Kambere, 2003; Nero, 2015). How might these language identities and vernaculars play out in a British Columbian context? The interview questions did not focus on language; however, language was mentioned by two of five preliminary piloted interviews. For example, a Trinidadian Canadian reflected on language as "part of one's Caribbean identity" and noted "giving that up" with migration.

\section{Research Process: Building on and with a Community Vision}

In this project, I will work with existing data; someone else framed and asked the questions. I need to honour someone else's desires and intentions while bringing my own sensibilities to the tasks. Perhaps this reality is a metaphor for the generative nature of the project, as archival data are meant to be used and reused (Moore, Salter, Stanley, \& Tamboukou, 2017). I shall use participants' real names: The interview project was originally conceptualized as a book-length document that celebrates Black contributions to Canadian society. However, while participants signed consent forms and are aware of the book project, new consent forms will need to be gathered, as the digital component was not envisioned in the initial consent process (L. Ringham, October 11, 2016).

\section{Building on Previous Questions}

The 2006-2007 interview questions probed "life stories." They focused on participants' backgrounds and lives in Vancouver, lessons learned, and ideas about preparing the next generation of Black Canadians. From these responses, I developed a set of questions based on the small preliminary study mentioned earlier; that is, I transcribed and analyzed five participants' audio-recordings, selected from a range of ages and backgrounds. With advice from the Department of Language and Literacy Education's Digital Literacy Centre, I transcribed only a few interviews lest I destroy the cassette tape quality before digitization (as mentioned earlier, all files are now digitized). Research designs are not static (Ristock \& Pennell, 1996). As the work progresses, more themes will emerge. At this time, based on the small pilot study, the following themes recurred in narratives: Migration, work, racism, education, family, community, identity, alienation, and activism. They were used to construct the following questions.

1. What have been the everyday conflicts, contradictions, challenges, and complexities for people living in Vancouver who identify as Black, in terms of migration, education, work, family, relationships, and identity?

2. How have societal dimensions (e.g., race, gender, nationality, class, ethnicity, religion, etc.) played a role in their aspirations, opportunities, and activism?

3. How do these participants negotiate their (diasporic) identities in British Columbia — a region that rarely acknowledges a Black presence? 
4. How does language (variation) play a role in the lives of Canadians from the African and African Caribbean diasporas?

Interviews will be analyzed inductively, using a qualitative software program (NVIVO) to assist in coding and theoretical sampling as well as in finding and organizing themes. The project will also take advantage of other computer-assisted ways of analyzing and working with oral history data, such as HTML tagging and open access tools that involve information search and retrieval methods. After these analytical processes have been completed, the construction of the archive will begin.

\section{Constructing a Digital Archive}

Having framed the project, let us now return to the main topic of constructing a community archive. An archive is a repository, writ large. As noted, "community archives" are often grassroots projects of collecting and curating materials of relevance to a community. The important work of Black communities often "remains silent in the professional archival literature” (Hopkins, 2008, p. 84). The very reasons communities take on such projects are often prompted by this absence and by the lack of materials and history made accessible for children and those not yet born.

Derrida (1996) believed that archives could be places of violence, reflecting state power and the voices of the powerful whilst silencing the marginalized-a kind of strategic 'forgetting.' The aim of this digital archive is to address this very violence, silencing, and strategic forgetting (Derrida, 1996). However, a researcher working with a community group can easily veer off those dangerous precipices she is trying to avoid due to divergent cultures, expectations, needs, goals, and power relationships. In what follows, political, cultural, and ethical issues are raised. Trust, ownership, and custodianship of community materials; representation of participants; the politics in researching one's community, as well as the politics of housing an archive-all are interwoven with power and equity.

\section{The Complexities of Insiderness}

I am a university researcher. I am a member of the Black community. I come to this community with a Caribbean, British, and Canadian background. I understand how the values and demands of the academic community may at times be dissonant with the everyday lives of Black people outside of the university. Elsewhere, I have discussed my commitments to this community (Henry, 1992, 2006). I have always tried to be "provalue" (Lather, 1986), prioritizing subjectivity and politics when conducting research. As part of my engaged scholarship and embodied practice, this digital project further allows me to be of use to a Black organization that supports Black women and families. The pleasure of working with this activist organization aside, I feel the responsibility of what Mari Carmen Ramirez (1996) calls the curator as "cultural-broker." In discussing art exhibitions, Ramirez (1996) notes that this role is meant to "uncover and explicate how the practices of traditionally subordinate and peripheral groups or emerging communities convey notions of identity” (p. 22). She adds, "curators can claim to be shaping a more democratic space where specific cultural groups can recognize themselves (p. 22).

As Black scholars who may espouse alternative cultural lenses (Collins, 2009), we are trained in institutions of higher learning with methodologies and ways of working that may not resonate with our communities in respectful, culturally appropriate ways (Henry, 
2006; Wiredu, 1996). As mentioned above, members of our communities may rightfully express ambivalence about the aims of university researchers, knowing that Black lives and communities have been misrepresented in social science and historical studies. Although I am using my positionality as a resource, my Blackness, femaleness, and Caribbean heritage do not guarantee a trusting relationship with this Black women's organization. As Twine (2000) suggests, racial insiderness "may simply create a different set of pluses and minuses, rather than eliminate them" (p. 13). Similarly, Subreenduth and Rhee (2010) note that "the colour of the body doesn't guarantee innocence, resistant points or authenticity as a voice for anti-oppression. In fact, different shades of a colour can be a source of discrimination and oppression in one's own community (p. 338).

The assumption of insiderness must be interrogated; there are multilayered dimensions of power, politics, and equity in all relationships. Michael Mitchell (2003) asks, "how does a social scientist balance the commitment to scientific detachment with the equally important commitment to praxis and to actually participating in a process of political change?” (p. 36). Perhaps a more fitting question for this digital project was posed by Maria Tamboukou (2017): "How can we understand the researcher and the archive as an entanglement rather than as separate and independent entities?" (p. 71). These are questions to be considered throughout this digital archive project.

\section{Trust: Erasing a History of Distrust}

Creators of Black community historical materials have had reason to distrust the intentions of outsiders (e.g., university researchers). From working in and with organizations, I know and understand the reasons that Black organizations may be reluctant to transfer their labour-intensive collections to people outside of their communities. As university researchers, we might need to expand our ways of being in and working with communities. Our collaborations should always benefit the communities in some way.

Although I have not witnessed a sense of distrust in this current project, these tensions can exist and are well documented in the literature (Ajamu, Campbell, \& Stevens, 2010; Bookey, 2007; Martin, 2005). In counterhegemonic acts of self-definition and selfrepresentation, some Canadian minoritized communities have taken on the charge to protect their own resources, preferring to work by themselves and bypass mainstream misrepresentation and outside control. ${ }^{3}$ The erroneous portrayals of Africans in the exhibition, 'Into the Heart of Africa,' mounted by the Royal Ontario Museum from 1989 to 1990, was a painful example of Black misrepresentation and an imperialist, colonialist curatorial approach (Hong, 2016). To avoid some of these pitfalls in our project, we cultivated a relationship over time.

\section{Ownership: "We want our name on it"}

NCBWF represents a safe space in which Black women can set their own priorities, address the needs of the community, work from a common standpoint, and maintain control

${ }^{3}$ Groups such as the Canadian Women's Documentary Heritage, the Canadian Women's Movement Archives (CWMA), and the Canadian Lesbian and Gay Archives (CLGA) are examples of successful institutions established to retain community control over their own records. Although marginalized, these groups typically have had more access, resources, and power than Black community organizations. 
over their projects. They share the same or similar life experiences and understandings. The organization has clearly expressed its expectations: The executive director, Ms. Callendar, asserted, "We want the credit. We want our name on it." Rightly so; the vision was theirs. They conducted the important first stages of the project. Moreover, the executive director's political statement reflects the ways in which Black people have had little control over the longevity of their work and the ways in which their stories have been co-opted. It is fundamental that NCBWF retain custody over, and credit for, the book and digital archive. Similarly, they must be acknowledged in any presentations or research. Ms. Callendar's statement serves as a reminder that we are working together-despite the fact that I (alongside others) will be carrying out various stages of the project at the University of British Columbia (UBC). This organization's community must have an equal voice in the aesthetics, process, and final products. The transfer of materials to my temporary custody has resulted from ongoing conversations about the importance of disseminating this ambitious, unique, and unfinished community effort. It is axiomatic to remain faithful to their desires throughout this process.

\section{Technology Reality Check: The Community is not the University}

Contemporary possibilities of working with data-what can be accessed, preserved, analyzed, and disseminated, and how these tasks can be carried out - are astounding. University researchers have access to the latest technologies in this rapidly changing digital climate. Our institutional privilege in the Faculty of Education at UBC allows us to always have the latest and newest hardware, in contrast to the ways in which many grassroots organizations carry out their work. Many community groups work with tight budgets and limited staff. They may not have the financial means to update software and hardware with the same frequency as universities and corporations. For example, the interviews for this project were recorded on microcassette audiotapes. Much has changed since 2006. Thus, our work required time for this data to be digitized and rendered compatible with the current technologies. Consider the following challenge: In order to work with the audiotapes, I needed a microcassette recorder/transcriber. Despite a university-wide call to the librarians and digital media departments, a microcassette transcriber was not to be found anywhere! How could we carry out our work? Luckily, doctoral student and coordinator of the Digital Literacy Centre, Ernesto Peña, had the foresight to confiscate an old recorder from an e-waste bin on a hunch that it may be useful someday-months before he or I knew we needed one! This example underscores how universities are quick to discard equipment that may be necessary for our work in partnership with outside organizations. We are divorced from the realities of community organizations that work with low-budgets and have limited access to the latest technologies. This discordance in access, funding, and human and material resources may lead to the inequitable expectations set by researchers.

\section{Race, Language, Voice and Digital Representation}

I once had the experience of sharing the transcript of an audio-recorded interview with a disbelieving research participant. She refuted the accuracy of the transcript. "I don't speak like that! These are all monosyllables,” she exclaimed. This raises issues concerning how one perceives one's speech and how one actually speaks, and well as how one's speech is represented in print. This is a particularly interesting issue with speakers of varieties of 
English, Creoles, and dialects. The 59 interviewees on these tapes come from many geographical locations, and some speak a variety of English. From my listening and reading of transcriptions to date, forms of "non-standard English" were found when participants made particular points or recounted a memory from their homelands. How does one represent these forms of language digitally and in print? How might transcripts with language variation, code-switching, or code-mixing be presented to the general audience or reader? To what degree might language varieties be made part of participants' digital stories? Transcribing language varieties thus may raise methodological and political questions (Gaillet, 2012; Henry, 2005). Although I previously mentioned that language was not a focus of the preliminary questions, I am nonetheless keeping alert to possible interesting findings and questions. Politics and power are implicated in how we use (digital) technologies in culturally sensitive ways to represent speakers' voices, histories, and meanings.

\section{Where Do We Belong? The Politics of Housing an Archive}

Initially, this digital archive will be housed on a server at UBC. The university will be the site of development. After much deliberation, I have begun to ask myself several questions regarding this setting: Does this location diminish the political significance of a Black community archive for, by, and about Black people? What are the implications of housing a Black community archive at an institution that has ignored-and, some might argue, mistreated - the Black community (e.g., Henry, 2015; Marchak, 1996)? Does it matter? It will be an online archive, after all. Accessibility will be ubiquitous. Yet these questions do matter when considering equity; power and politics pervade these processes and products. Questions need to be raised every step of the way when thinking of digital equity and community empowerment.

\section{Concluding Remarks: A 'Living Archive of the Diaspora'}

Borrowing from Stuart Hall (2008), I envision this project to be a "living archive of the diaspora" (p. 89). Living. Archive. Diaspora. All are equally important. "Living" denotes that the archive is ongoing, unfinished, and open-ended. The interviews constitute the first step - the raw material-in creating the digital archive. The project is ripe for multidimensional, intertextual cross-pollinations with various creative forms, as well as for additional updated materials. Crucially, this digital collaboration is poised to contribute to the historical and cultural memory of African Canadians in Vancouver and to a muchneeded cultural and racial literacy in Canada. Just as importantly, the project reminds us as researchers that our digital community collaborations are delicate and joyous endeavours, through which we must seriously consider our ethics, engagements, and entanglements.

\section{References}

Ajamu, X., Campbell, T., \& Stevens, M. (2010). Love and lubrication in the archives, or rukus!: A black queer archive for the United Kingdom. Archivaria, 68, 271-294.

Bookey, T. (2007). “1967 and all that” \& the LGBT community. ARC, 21-22.

Collins, P. H. (2009). Black feminist thought: Knowledge, empowerment and Consciousness. New York: Routledge.

Compton, W. (2001). (Ed.). Bluesprint: Black British Columbian literature and orature. Vancouver, BC: Arsenal Pulp Press. 
Compton, W. (2002). The Hogan’s Alley Memorial Project. Retrieved from http://hogansalleyproject.blogspot.ca

Compton, W. (2006). Unpublished transcription of audio interview. (S. Vidal, interviewer).

Compton, W. (2007). The diaspora's upper left-hand margin: Octopus and callaloo. Callaloo, 30(3), 793-794.

Compton, W. (2011). After Canaan: Essays on race, writing, and region. Vancouver: Arsenal Pulp Press.

Creese, G. (2015). Growing up where “no one looked like me:” Gender, race, hip hop and identity in Vancouver. Gender Issues, 32(3), 201-219.

Creese, G. \& Kambere, E. N. (2003). "What colour is your English?” Canadian Review of Sociology/Revue Canadienne de Sociologie, 40, 565-573. doi: 10.1111/j.1755618X.2003.tb00005.X

Crenshaw, K. (1991). Mapping the margins: Intersectionality, identity politics, and violence against women of color. Stanford Law Review, 1241-1299.

DeLoughrey, E. (2007). Routes and roots: Tidalectics in CaribbeanlLiterature. In A. Paul (Ed.), Caribbean culture: Soundings on Kamau Brathwaite (pp. 163-175).

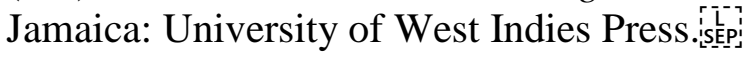

Derrida, J. (1996). Archive fever: A Freudian impression, (E. Prenowitz, Trans.). Chicago, IL: University of Chicago Press.

Feldman, H. (2006). Black rhythms of Peru: Reviving African musical heritage in the Black Pacific. Middletown, CT: Wesleyan University Press.

Flinn, A. (2007). Community histories, community archives: Some opportunities and challenges. Journal of the Society of Archivists, 28(2), 151-176. DOI: 10.1080/00379810701611936

Gaillet, L. (2012). (Per)forming archival research methodologies. College Composition and Communication, 64(1), 33-58.

Hall, S. (2008). Whose heritage? Un-settling 'the heritage,' re-imagining the post-nation. In J. Littler \& R. Naidoo (Eds.), The politics of heritage: The legacies of 'race' (pp. 21-31). London, UK: Routledge.

Hendry, P. M. (2010). Narrative as inquiry. The Journal of Educational Research, 103, 72-80.

Henry, A. (1996). Five Black women teachers critique child-centered pedagogy: Possibilities and limitations of oppositional standpoints. Curriculum Inquiry, 26(4), 363-384.

Henry, A. (2005). Writing in the margins of classroom life: A teacher/researcher partnership using dialogue journals. S. Schecter and L. Alvarez (Eds.), Learning, teaching, community (pp. 69-87). Mahwah, NJ: Erlbaum.

Henry, A. (2006). Historical studies: Groups/institutions. In G. Camilli, P. Elmore, \& J. Green, (Eds.), Complementary methods for research in education (pp. 271-293). Washington, DC: American Educational Research Association.

Henry, A. (2015). 'We especially welcome applications from members of visible minority groups': Reflections on race, gender and life at three universities. Race Ethnicity and Education, 18(5), 589-610.

Hong, J. (2016, November 9). ROM apologizes for racist 1989 African exhibit. Toronto Star. Retrieved from https://www.thestar.com/news/gta/2016/11/09/rom- 
apologizes-for-racist-1989-african-exhibit.html.

Hopkins, I. (2008). Places from which to speak. Journal of the Society of Archivists, 29(1), 83-109.SEP:

James, C. \& Davis, A. (2013, July). Instructive episodes: The shifting positions of the Jamaican diaspora in Canada. Paper presented at the High Commission of Canada, Kingston Jamaica.

Jones-Darrell, O. (Director and Music). (2017, June 26). James Douglas: An opera [Radio Drama]. GoldCorp Centre, Vancouver, B.C.

Lather, P. (1986). Research as praxis. Harvard Educational Review, 56(3), 257-278.

Marchak, P. (1996). Racism and sexism at University: The political science affair at the University of British Columbia. Montreal, QC: McGill-Queen's Press.

Martin, S. I. (2005). Inheriting diversity: Archiving the past. In J. Littler and R. Naidoo (Eds.), The politics of heritage: The legacies of 'race' (pp. 175-179). London, UK: Routledge.

McKittrick, K. (2002). Their blood is there, and they can't throw it out: Honouring black Canadian geographies. Topia, (7), 27-37.

Mitchell, M. (2003). Changing racial attitudes in Brazil: Retrospective and prospective views. National Political Science Review, 9, 35-51.

Moore, N., Salter, A., Stanley, L., \& Tamboukou, M. (Eds.). (2017). The Archive project. Archival research in the social sciences. London, UK: Routledge.

Nero, S. (2015). Language, identity, and insider/outsider positionality in Caribbean Creole English research. Applied Linguistics Review, 6(3), 341-368.

Nóvoa, António. (1995). On history, history of education, and history of colonial education. Paedagogica Historica, 31.sup1, 23-64.

Okihiro, G. (2006). Toward a Black Pacific. Afterword. In H. Raphael-Hernandez \& S. Steen, S. (Eds.), AfroAsian encounters: Culture, history, politics (pp. 313-330) New York, NY: New York University Press.

Okihiro, G. Y. (2001). Reflections of self and society. Radical History Review, 2001(79), $111-113$.

Razack, S., Smith, M., \& Thobani, S. (2010). States of race: Critical race feminism for the 21st century. Toronto, ON: Between the Lines.

Ramirez, M. C. (1996). Brokering identities: Art curators and the politics of cultural representation. In R. Greenberg, B. Ferguson \& S. Nairne (Eds.), Thinking about exhibitions (pp. 21-38), London, UK: Routledge.

Ristock, J. \& Pennell, J. (1996). Research as empowerment. Toronto, ON: Oxford University Press.

Salvatore, N. (2004). Biography and social history: An intimate relationship. Labour History, 87, 187-192. Doi:10.2307/27516005

Scott, D. (2008). Introduction: on the archaeologies of black memory. Small Axe, 12(2), $\mathrm{V}-\mathrm{Xvi}$.

Shilliam, R. (2015). The Black Pacific: Anti-colonial struggles and oceanic connections. London, UK: Bloomsbury Publishing.

Smyth, H. (2014). The Black Atlantic meets the Black Pacific: Multimodality in Kamau Brathwaite and Wade Compton. Callaloo, 37(2), 389-403. 
Statistics Canada. (2010). Projections of the Diversity of the Canadian Population: 20062031. Catalogue no. 91-551-X. Ottawa, Ontario, Canada. Retrieved from http://www.statcan.gc.ca/pub/91-551-x/91-551-x2010001-eng.pdf

Subreenduth, S., \& J. E. Rhee. (2010). A porous, morphing, and circulatory mode of selfother: Decolonizing identity politics by engaging transnational reflexivity. International Journal of Qualitative Studies in Education, 23(3), 331-346.

Tamboukou, M. (2017). Archival rhythms: Narrativity in the archive. In N. Moore, A. Salter, L. Stanley, \& M. Tamboukou (Eds.), The archive project: Archival research in the social sciences (pp. 71-96). London, UK: Routledge.

The Environics Institute (2017). The Black Experience Project in the GTA. Toronto, July. Retrieved from http://edu.yorku.ca/files/2014/06/Black-Experience-Project-GTAOVERVIEW-REPORT.pdf

Trotz, A. \& Mullings B. (2013). Transnational migration, the state, and development: Reflecting on the "Diaspora Option." Small Axe, 41, 154-171.

Twine, F. W. (2000). "Racial ideologies and racial methodologies.” In F. W. Twine \& J. Warren, (Eds.), Racing research, researching race: Methodological dilemmas in critical race studies, (pp. 1-34). New York, NY: University Press.

Wiredu, K. (1996). Cultural universals and particulars: An African perspective. Bloomington, IN: Indiana University Press.

Zeleza, P. (2008). The challenges of studying the African Diasporas. African Sociological Review, (12)2, 4-21. 